\title{
Gender Specific English Advertisements
}

\author{
Ruzanna Arakelyan, Ani Petrosyan \\ Yerevan State University
}

\begin{abstract}
Advertising is a worldwide phenomenon nowadays that has gained the attention and interest of a large number of individuals in different societies around the world. Advertising is not only an "ideal tool" for reaching people economically, but also a device of attaining and maintaining contact with people socially, culturally, politically and even psychologically. As men and women perceive various social phenomena and often react to certain situations in quite distinct ways, it is also vividly expressed in the ways they perceive the effectiveness of advertising language. This is also conditioned by the fact that men and women create different imagery from the advertisements they see. This confirms the fact that ad specialists should analyze how they choose the target viewers and what language they should use to focus on them. Thus, gender is one of the main segmentation variables for the advertiser, and a significant factor that makes it interesting to advance the study of how gender differences are manifested in the language of advertisements.
\end{abstract}

Key words: advertising, gender language, gender differences and perceptions, communicative power of language.

\section{Introduction}

The main topic of this research is the gender difference in perception of ads and gender specification in the language of advertising. Advertising is a worldwide phenomenon that has gained the attention and interest of a large number of individuals in different societies around the world. We also know that men and women are different in their characteristics, behavior, characteristics, way of thinking and tactics, that is to say, the way they act, and in using the language, 
the way they speak. Thus it is not surprising that gender is reflected in advertisements as well.

To start with, it should be mentioned that gender can be defined as a set of social and cultural norms and practices that the society prescribes to human individuals according to their sex. Men and women perceive various social phenomena and often react to certain situations in distinct ways. There are even differences between male and female brains. Although men tend to have larger brains, they shrink more quickly as old age sets in. One of the most significant differences is the fact that females' brain has more connections between the right and left halves. Because there are more connections, women are able to recover from a stroke much easier than men since their brain has more options for rerouting signals. According to Lakoff and Spender (1980), women's speech is characterized "as more hesitant, less fluent, less logical, and less assertive than men's speech. Women, in their view, are more silent, interrupt less frequently than men, use tag questions and modal verbs more than men, use cooperative strategies in conversations rather than competitive ones, and so on." Therefore, men's and women's choices of conversation content, language use or speech style are not different only because of their different sexes, but also because of their socio-cultural background and social status etc (Mills 1995).

\section{Gender Difference in Perception of Ads}

Women and men have some differences at the level of discourse and conversation as well. Men interrupt women in a group where men and women are interlocutors. Women frequently accept men's topics while men reject subjects raised by women. Women are more polite than men and try most of the time to initiate conversation but succeed less because of men's lack of cooperation. The confirmation, according to Cross \& Markus (1993), is that "women's linguistic styles also reflect a sensitive connection to the other. For women, the goal in social interaction is often cooperation and support." Grammatically, women use more tag questions, more hedges, direct quotations, more descriptive adjectives, more intensifiers and incomplete sentences. 
Ads are often more detailed for women. For example, in toiletry ads, women appreciate very fine distinctions such as shampoos for dry hair, for straight hair, for curly hair, for oily hair, etc. There are fundamental differences in the way men and women perceive information. Women tend to process different pieces of information more extensively. Men rely more on mental shortcuts. Females consider detailed, subjective advertisements aimed towards appealing more to the affective, emotional state to be of higher preference. In a Yarborough study a group of people were brought to a room and later asked to remember various items there. The result showed that women had much better memory for details than did men. Men might remember the big picture of an office like the location of a desk or a bookshelf. But women would remember more intimate details like a vase of flowers in the corner or a picture of a husband, etc (Yarborough 2000).

However different gender ads, they are designed with only one intention: to make more profit by bringing the products to groups of potential customers. To achieve that intention effectively, they "characterize" the potential customers of each product or service and design "personalized" advertisements that target at certain potential groups of customers (<http://www.choicestream.com $>$ ).

The most important techniques that all advertisement designers need to know are the techniques of choosing the target viewers and language wisely and correspondingly. Language plays a vital role in the society in general and in everyone's life in particular. We use language of all kinds every day, every moment to communicate with other people, to get ourselves and our own opinions expressed and vice versa - to get the same things from others (Gyllgard 2006).

\section{Gender Specification in the Language of Advertising}

Mastering the communicative power of language, sensible advertisers try to utilize language as a powerful tool to influence the viewers. More specifically, they often try to use language distinctively in order to catch the viewers' attention. (<https://www.adcracker.com $>$ ) For example, advertisers sometimes play with words, use them out of context, use some ambiguous meanings of 
words, put specific metaphors and create new ones in order to help and manipulate viewers. In most cases those words become slogans for brands. In Mac cosmetics it is Discover Ideas about All Races, for Michael Kors it is Women can't drive. The mentioned ads do not clearly feature a product being advertised. The second ad symbolizes the idea that women's sole responsibility is beauty while men carry the burden of work.

Sentence structure is also important to draw customers' attention. A sentence as why don't you try...? is found regularly in female advertising, grammatically it is an interrogative sentence but intends to issue a direction to customers. In contrast, a direct sentence like an imperative is generally used in male advertisements. Men do not use indirect sentences much in daily life and sometimes have a problem with interpretation. The sentence structures are already chosen suitably for each target "victim". Clear shampoo is one obvious example in Vietnam: the product has seven advertisements on television and the Internet. They seem to target different viewers of different genders and have several other aspects such as models, images, languages and advertising techniques. The analysis of advertisements, taken from TV and the Internet, shows that male models talk about their confidence and show their strength as well as their dominance to others by facing a certain problem: For example:

I breathe. I move. I sweat. With the world watching. My hair. My clothes. I like black. Black is confident. Black looks good. Looking good means no dandruff. Confidence means no dandruff. Clear means no dandruff. I trust Clear. Dandruff never comes back. My name is Rain. Clear. No Dandruff. This means that black is confident, confidence means no dandruff.

As their concerns are different, female and male models choose different adjectives when they speak about their hair. Like in the above ad, most male models and voiceovers use black to talk about their hair or the hair they want to have (I like black. Black is confident. Black looks good). 
At the same time, female models talk about the features of soft, clean and beautiful which are just suitable to describe female hair.

Clear makes my hair soft and beautiful. Just soft hair.

Can your shampoo leave your hair soft and clean? Clear takes it soft. Just soft hair.

As can be seen from the above-mentioned advertisements, female models talk with a collaborative orientation. They talk as if they want to share their experience with the audience whereas male models and voiceovers try to assert their positions of dominance by a competitive orientation. Men, for example, talk about their dealing with dandruff, the collision of sparks and dandruff, their black seduction and temptation when they are dandruff free. The tendency of dominance is also expressed by short imperative sentences which can be found more frequently in male models' or voiceovers' speech:

Face it. Solve it.

Rage, rage against her breath of fear.

Make the season more seductive. Make it a Clear Black

Valentine's. Be board. Be Black. Move closer anytime. Have

Clear Black Valentine's.

Advertisements with male models offers another typical feature of a male speech. That is the logic in thinking and speaking. Using logical speech, male models try to convince the audience that, for example, there is a close relationship between being clear, black, confident and looking good.

\section{Conclusion}

The notion of advertising is nothing new. It is a worldwide phenomenon and expanding throughout the world nowadays. Advertising is also described as an audio or visual form of marketing communication that employs an openly sponsored, non-personal message to promote or sell a product, service or idea.

To conclude, it can be stated that 
- Language, gender and society are three complex and closely interwoven notions, though many studies have focused on the differences existing between men and women in terms of social behavior and language use.

- Gender is defined as one of the primary categories that people use to understand and think about their social world. Language is an important part of an individual's life which helps to form social identity by different linguistic habits reflecting different individual biographies and experiences.

- Advertisers have some techniques: they use language in marketing based on different stereotypes of gender to convince customers to buy products. And this really works, because men and women have different gender stereotypes to convince customers to buy products.

- Advertisements for women contain a lot of declarative adjectives, whereas they are hardly found in ads for men. Advertisements for men usually use simple words which do not have many adjectives and are easy to understand. Advertisers use descriptive words frequently in women skin care and cosmetic advertisements. It is a great strategy which effectively attracts customers. A sentence like why don't you try...? is found regularly in advertisements for women, actually, it is an interrogative sentence but intends to issue a direction to customers. In contrast, a direct sentence like an imperative is generally used in advertisements created for men.

No matter how different advertisements are, they are designed with only one intention: to make more profit by bringing the products to groups of potential customers. To realize that intention quickly, they characterize the potential customers of each product or service and by means of specific linguistic means design personalized advertisements that target certain potential customers.

\section{References:}

1. A Guide to Progressive Gender Portrayals in Advertising. Available at: <http://www.choicestream.com> [Accessed April 2019]. 
2. Bruner, J.S. (1957) On Perceptual Readiness, Psychological Review, Washington: American Psychological Association.

3. Communicative Power of Language. Available at: <http://www.adcracker.com> [Accessed March 2019].

4. Cross, S.E. \& Markus, H.R. (1993) Gender in Thought, belief and Action: A Cognitive Approach. New York, US: Journal of Advertising Research: Guilford Press.

5. Dholakia, R. \& Kshetri, N. (2003) Gender \& Internet Usage. US: Guilford.

6. Geis, M.L. (1993) A Social Psychological View of Gender. US: Guilford.

7. Lakoff, R. \& Spender, D. (1980) Gender Styles in Computer Mediated Communication, New York: OUP.

8. Sara, M. (1995) Feminist Stylistics, London: Routledge.

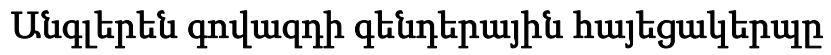

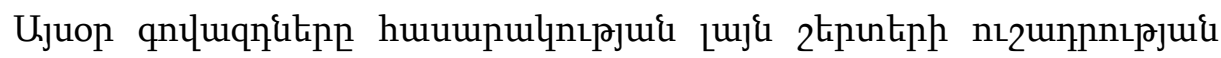

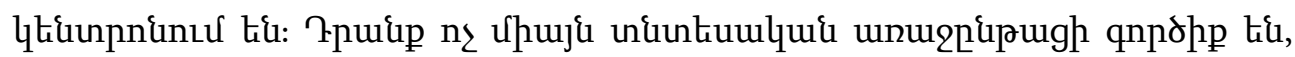

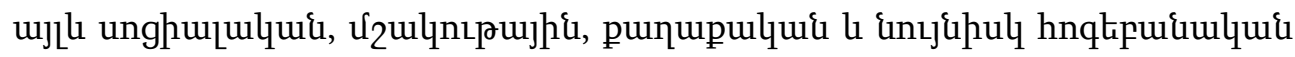

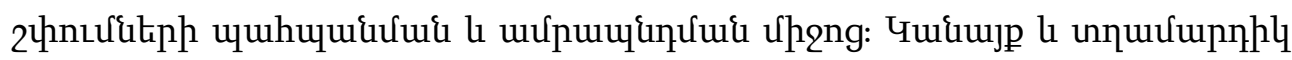

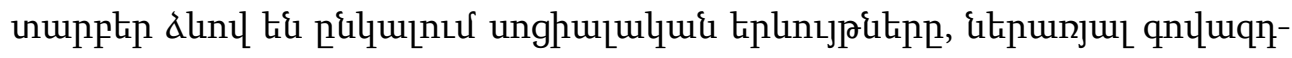

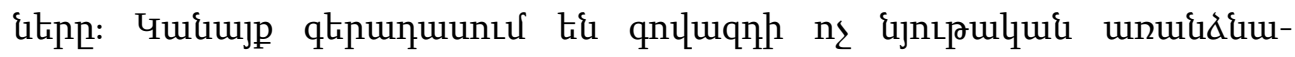

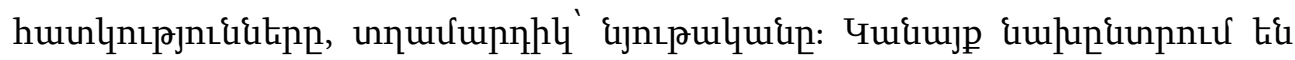

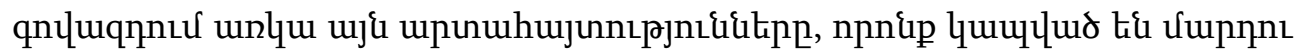

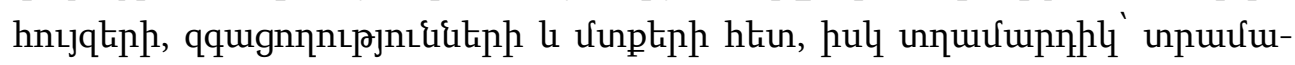
puinıpju\{, opjtilunhl huunlnıpjnı\&\&itph, quphtpujh, uunpunh, htinuqn-

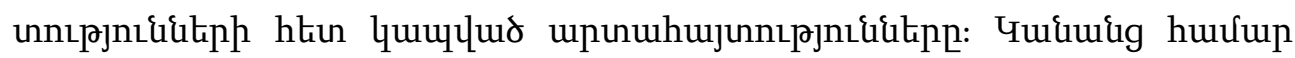

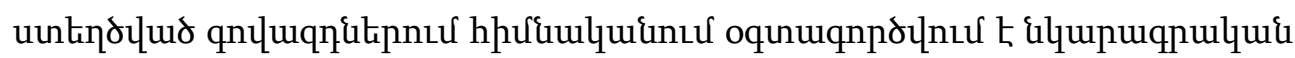

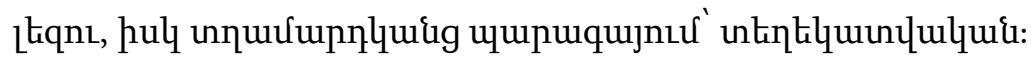

Received by the Editorial Board 12. 09.2019

Recommended for publication by the reviewers 15.11.2019

Accepted for print 13.01.2020 